\title{
Nanostructure of Deep Eutectic Solvents at Graphite Electrode Interfaces as a Function of Potential
}

\author{
Zhengfei Chen, ${ }^{1}$ Ben D. McLean, ${ }^{1}$ Michael Ludwig, ${ }^{1}$ Ryan Stefanovic, ${ }^{1}$ Greg G. Warr, ${ }^{2}$ \\ Grant B. Webber, ${ }^{1}$ Alister J. Page, ${ }^{1}$ Rob Atkin*1 \\ ${ }^{I}$ Newcastle Institute for Energy and Resources, The University of Newcastle, Australia \\ ${ }^{2}$ School of Chemistry, The University of Sydney, Australia
}

Supporting information
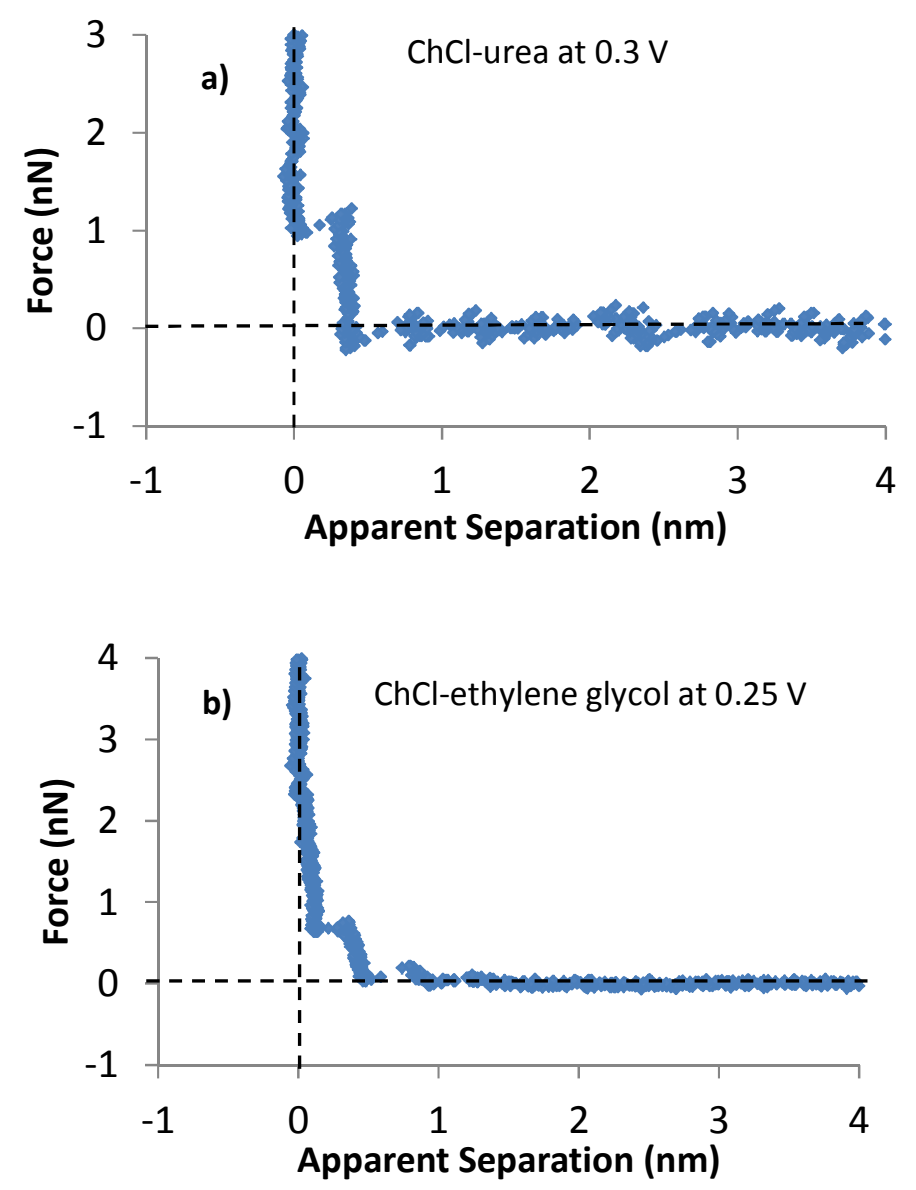


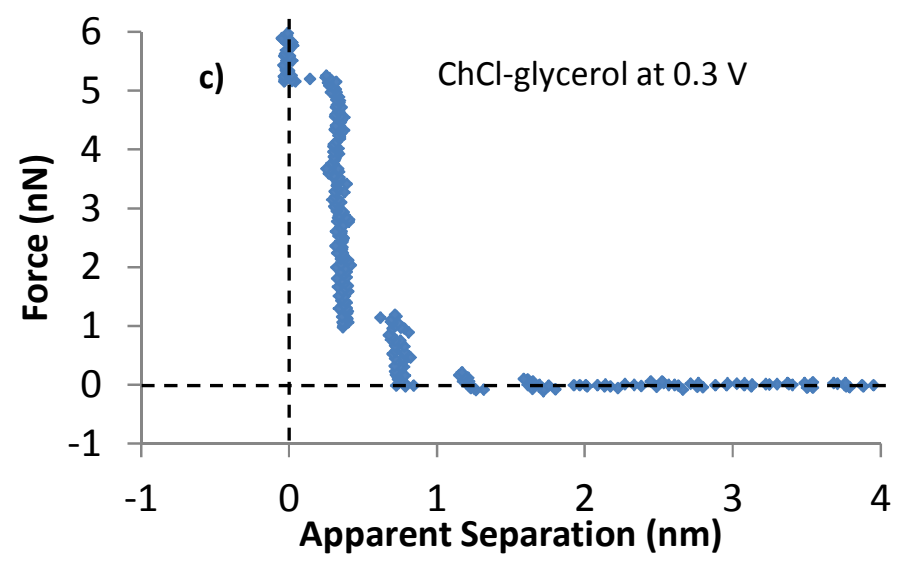

Figure S1. Normal force distance profiles for a) $\mathrm{ChCl}$ : glycerol at $0.3 \mathrm{~V}$; b) ChCl-ethylene glycol at $0.25 \mathrm{~V}$ and c) $\mathrm{ChCl}$-glycerol at $0.3 \mathrm{~V}$ on graphite. 